\title{
Horseradish Peroxidase Uptake In Vivo by Neuronal and Glial Lysosomes
}

\author{
O. Z. Sfilinger and Patricia D. Petiet ${ }^{1}$ \\ Mental Health Research Institute, University of Michigan Medical Center, \\ Ann Arbor, Michigan 48104
}

Received August 12, 1972

\begin{abstract}
Horseradish pcroxidase (HRP) was injected intracerebrally to immature rats, once a day for 3 days. The animals were killed $24 \mathrm{hr}$ after the last injection and the cellular and intracellular localization of the enzymatic tracer in the cerebral cortex was investigated by ultrastructural cytochemistry at the light and electron microscopic level as well as biochemically. By light microscopy it could be shown that the neuronal cell bodies and their dendritic processes took up the HRP tracer selectively and that its intracellular disposition remained confined to the cytoplasm. The HRP reaction product also appeared in neuroglial cells. Microperoxidase, a small molecular weight tracer, whose presence in cells can also be demonstrated by the cytochemical technique used for the demonstration of HRP activity, also entered neuronal cell bodies readily but, unlike HRP, it invaded their space rather indiscriminately including the nucleus. The segregation of HRP in the lysosomes of both neuronal cell bodies and neuroglial cells was demonstrated by electron microscopy. No evidence could be secured for the presence of HRP-positive reaction product in any other intraperikaryal organelle or inside nerve terminals. Oligodendrocytes appeared to concentrate HRP-reaction product in their lysosomes somewhat more avidly than the neurons. Additional evidence for the segregation of HRP in the neuronal lysosome was obtained by demonstrating its presence in neuronal cell bodies isolated in bulk by a recently developed technique. This was accomplished both at the level of the electron microscope and, concurrently, by measurements of HRP activity in homogenates and subcellular fractions prepared from the bulk-isolated neuronal cell bodies. Finally, the association of the injected HRP with a lysosome-rich subfraction obtained by differential and density gradient centrifugation of neuronal homogenates was also established. An incidental observation was the marked reduction, as a result of the repeated administration of HRP to rats 4 or 5 days old, of the specific
\end{abstract}

1 This investigation was supported by a Grant from the National Institute of Neurological Diseases and Stroke (NS-06294). The expert technical assistance of Mrs. Josephine C. Santiago is gratefully acknowledged. 
activity of the neuronal lysosomal enzyme, $N$-acetyl- $\beta$-D-glucosaminidase. This reduction was found to be accompanied by a severe retardation of the animals' growth.

\section{INTRODUCTION}

In recent years the development of procedures for the bulk-isolation of neuronal cell bodies and neuroglial cells from mammalian brain $(2,8,10$, $12,22,25,28,29,33$ ) has led to the recognition of distinct and, presumably, cell-specific biochemical differences between these two types of brain cells. Mostly, activity differences between selected enzymatic systems present in both cell types, viz., the membrane-bound ATPases (19), the mitochondrial succinate and $\alpha$-glycerophosphate dehydrogenase (35) and several lysosomal hydrolases (36) (see, however, 16) have been reported. More significantly, Radin et al. (26) recently noted the absence of the enzymatic activity synthesizing glucocerebroside from mature neuroglial cells of the rat cerebral cortex. A host of functional $(2,9,10,19,33,35)$ and compositional differences among the various classes of neuronal (23, $27,38)$ and glial (25) lipids have also been described.

Holtzman and Peterson (14) observed an active uptake of exogenous horseradish peroxidase by neurons of mouse dorsal root ganglia in culture, Becker et al. (1) examined the uptake of implanted horseradish peroxidase (HRP) crystals by the neurons of the rat cerebrum, Olsson and Hossmann (24) noted the occasional entry of HRP into neuronal cell bodies and processes after its intravenous administration to cats and rats, and Lane and Treherne (18) showed the preferential uptake of HRP by the glial cells in the desheathed ganglia of the central nervous system of the cockroach. A review of the cytochemical literature dealing with protein transport in the nervous system has recently appeared (13).

The present report describes results of experiments designed to demonstrate the uptake of intracerebrally administerd HRP by the neurons and neuroglial cells of the cerebral cortex of the immature rat, the intralysosomal disposition of the tracer in these two cell types, and the presence of peroxidase activity in isolated neuronal cell bodies and in a fraction of highly purified neuronal lysosomes.

\section{MATERIALS AND METHODS}

Twelve 2-day-old male Sprague-Dawley rats were lightly anesthesized with diethyl ether and about $40 \mu \mathrm{l}$ of HRP dissolved in $0.9 \% \mathrm{NaCl}$ was injected intracerebrally. A 27-gauge needle was used for the injections, which were made once daily for 3 days. Four rats received $5 \mathrm{mg}$ each; four $10 \mathrm{mg}$ each; and four $15 \mathrm{mg}$ each of HRP. The peroxidase prepara- 
tions used were type II or type VI (Sigma Co.). Two rats were injected repeatedly, as described above for HRP, with microperoxidase (MP), ${ }^{2}$ one rat receiving a total of $3 \mathrm{mg}$, and the other a total of $10 \mathrm{mg}$. Four 2-day-old male rats were used as controls and were injected daily with about $50 \mu \mathrm{l}$ of $0.9 \% \mathrm{NaCl}$. Twenty-four hours after the third injection, the rats were decapitated and the cerebral hemispheres rapidly removed.

Samples taken from the cerebral cortices of the animals receiving the different doses of HRP and MP were cut in coronal sections, $3 \mathrm{~mm}$ thick, and were fixed for $4 \mathrm{hrs}$ in ice-cold $5 \%$ glutaraldehyde, $0.1 \mathrm{~m} \mathrm{Na}$ phosphate buffer and $5 \%(\mathrm{w} / \mathrm{v})$ sucrose. The $\mathrm{pH}$ of the fixative was 7.4 . The blocks were washed for $48 \mathrm{hr}$ in cold 0.1 м $\mathrm{Na}$ phosphate buffer, pH 7.4.

Frozen sections, $10-12 \mu \mathrm{m}$ thick, were prepared and free-floating sections incubated for peroxidase activity with $3,3^{\prime}$-diaminobenzidine as substrate at room temperature in accordance with the procedure described by Graham and Karnovsky (11). The sections from the rats injected with HRP were incubated for $30 \mathrm{~min}$ while those taken from the rats receiving MP were incubated for $3 \mathrm{hr}(7)$. The sections were mounted on albuminized slides, air dried, counterstained with $1 \%$ methyl green in 0.1 M veronal acetate buffer, $\mathrm{pH} 4.0$, dehydrated, mounted and examined under the light microscope.

For electron microscopy, small portions of the cerebral cortex taken from the rats injected with 10 or $15 \mathrm{mg}$ of HRP were finely minced in a solution of cold $2 \%$ glutaraldehyde, which was $0.1 \mathrm{~m}$ in $\mathrm{Na}$ phosphate buffer and contained $5 \%(\mathrm{w} / \mathrm{v})$ sucrose. The final solution had a $\mathrm{pH}$ of 7.4 . The pieces were then fixed in a fresh cliange of the above fixative for $2 \mathrm{hr}$

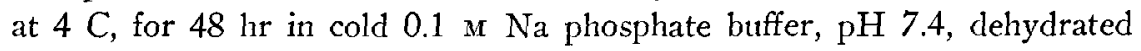
with ethanol and embedded in Epon 812. Ultrathin sections were cut on a Porter-Blum rotary microtome with glass knives, placed on naked 200mesh copper grids and stained lightly with $6 \%$ lead citrate in distilled water, $\mathrm{pH}$ 12.0. The sections were examined in a JEM VI electron microscope. The preparation for the electron microscopy, of the neuronal cell bodies and of a lysosome-rich subcellular fraction was as previuusly described $(16,17)$.

Highly purified neuronal cell bodies were isolated by the procedure of Sellinger et al. (33), described in somewhat more detail by Johnson and Sellinger (17). Homogenates of the neuronal cell bodies in $0.25 \mathrm{~m}$ sucrose were fractionated using the centrifugation schedule outlined by Sellinger and de Balbian Verster (30). The mitochondrial and the lysosomal fractions, isolated as pellets, were each suspended in $2 \mathrm{ml}$ of $0.25 \mathrm{M}$ sucrose

2 Lot $12-69 \mathrm{~A}$, kindly provided by Dr. Ned Feder, National Institute of Arthritis and Metabolic Diseases, Bethesda, Maryland $(6,7)$. 
and the suspensions layered on a linear density gradient of sucrose $(35-60 \%, w / v)$ prepared in cellulose nitrate tubes of $13.2 \mathrm{ml}$ capacity to fit the rotor SW-41 of the Spinco ultracentrifuge model L3-50. Centrifugation was for $14.5 \mathrm{hr}$ at $49,000 \mathrm{~g}$. Collection of the gradients and monitoring of the effluent at $280 \mathrm{~nm}$ was carried out as described previously (32).

The procedure described by Straus (37), with $N, N^{\prime}$, dimethyl- $p$-phenylenediamine $\mathrm{HCl}$ (purified grade III, Sigma Chem. Co.), as substrate was used for the demonstration of peroxidase activity in the isolated neuronal cell bodies and their subfractions. The final volume of the assay medium was $5.35 \mathrm{ml}$. The activity of $N$-acetyl- $\beta$-D-glucosaminidase, a marker enzyme of the neuronal lysosome was determined according to Sellinger ct al. (31).

\section{RESULTS}

Morphological Evidence for the Presence of HRP in Neurons and Neuroglia. Evidence for the entry of HRP into neurons (Fig. 1A-F) is illustrated by the positive staining response of several groups of cells. When a total of $5 \mathrm{mg}$ of IIRP (type II) was administered, the peroxidase reaction was moderate and was characterized by a rather granular deposition of the reaction product in the cytoplasm of some, but by no means all. neurons; few selected neurons were stained intensely, and reaction product rarely extended into the processes. There was no staining of the nucleus. At a higher dose (15 mg of HRP) the staining remained selective but a relatively larger number of cells and processes stained intensely than was the case at the low dose. A higher power view (Fig. 1E, F) shows a heavy accumulation of the reaction product in selected neurons, in contrast to the virtual absence of any staining in neurons contiguous to these. Nuclear staining was again absent. The HRP reaction product was also seen within the cytoplasm of pia mater and endothelial cells and, more rarely, in the apical portions of the cells of the choroid plexus. A few neuroglial cells were also lightly stained, but a precise morphological identification of the cell types involved proved difficult at the level of resolution provided by light microscopy. The results of the administration of MP (Fig. 1G, H) show that in the single rat given $3 \mathrm{mg}$ of this tracer, cortical neurons were rarely and, when so, only lightly stained. However, sections taken from the cortex of the rat injected with $10 \mathrm{mg}$ of MP showed that the tracer readily entered selected neuronal perikarya and neuroglial cells; unlike the picture after the administration of HRP, MP penetrated the nuclear membrane quite freely, giving rise to indiscriminate staining which involved the entire cellular mass.

Electron microscopy revealed the apparent segregation of the injected HRP into the lysosome like bodies in both neurons and neuroglia. Since 


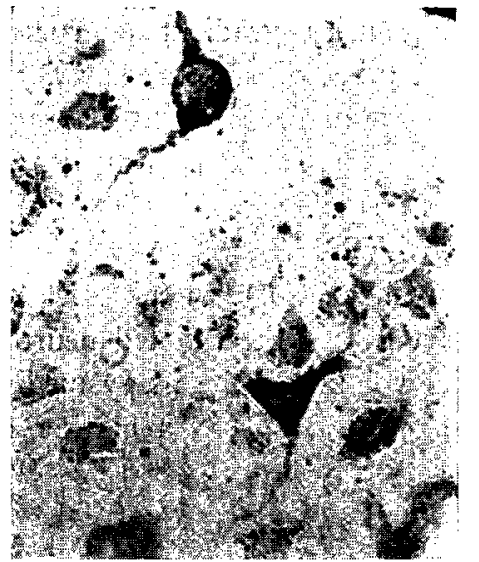

(a)

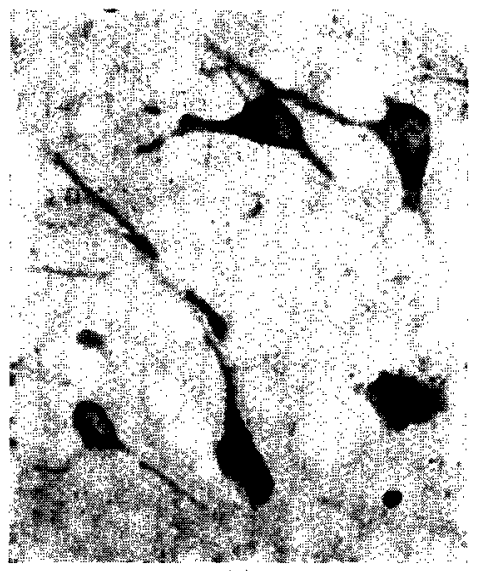

(c)

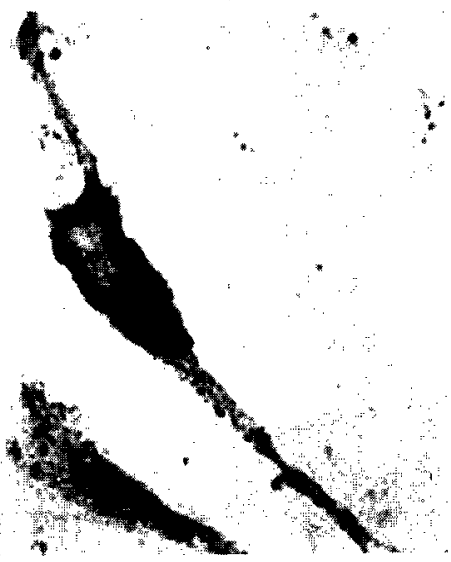

(e)
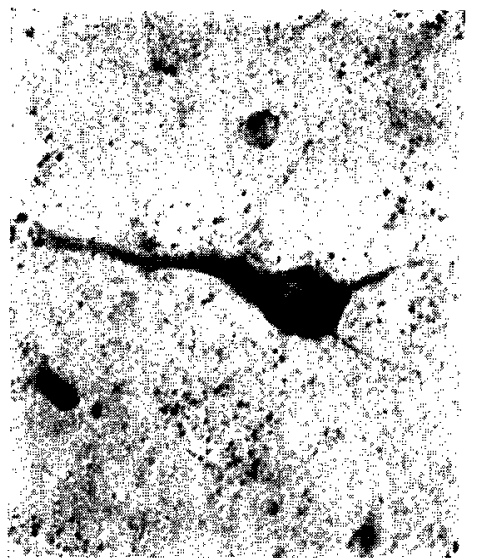

(b)

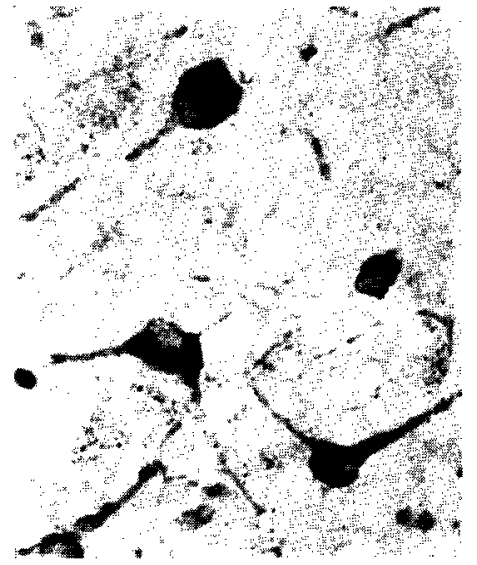

(d)

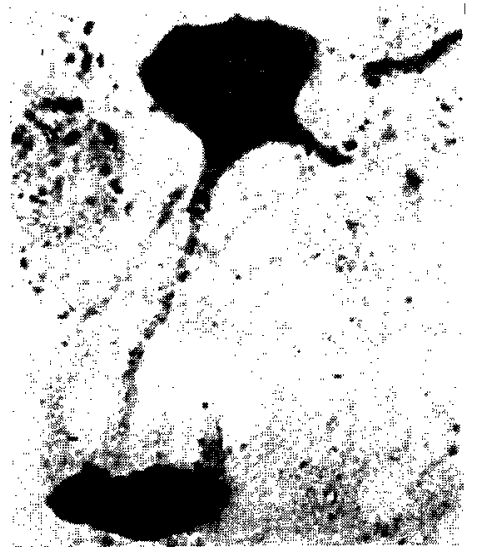

(f)

FIG. 1 A-F. A. Five milligrams of HRP (type II) were injected intracerebrally once a day for 3 days and the rats were killed 24 hr after the last injection, on day 


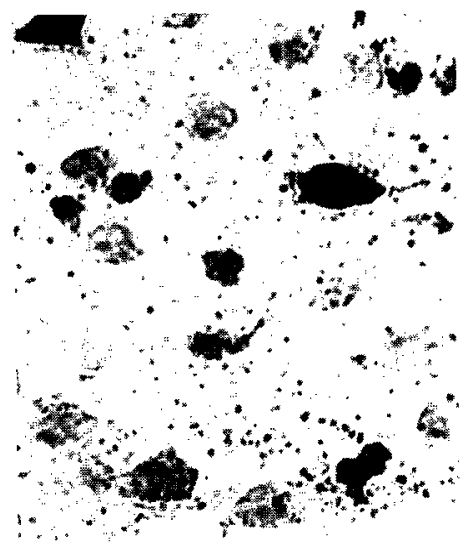

(g)

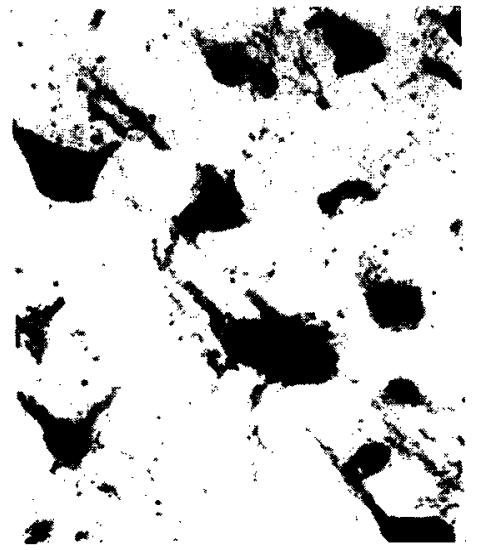

(h)

Fig. 1, G, H. G. Microperoxidase ( $3 \mathrm{mg}$ ) was injected intracerebrally, once a day, for 3 days and the animals were killed $24 \mathrm{hr}$ after the last administration, on day 5 . Note the very irregular pattern of staining, which blackened two neurons compietely but stained the remaining ones only mildly, if at all. Also note the total involvement of the nuclear space. $\mathrm{H}$. Microperoxidase $(10 \mathrm{mg})$ were administered. Staining is intense and indiscriminate. $G, H, \times 1000$.

the topographic localization of the IIRP reaction product varied somewhat, the diversity of the sites containing HRP reaction product is illustrated in Fig. 2A-F. Figure 2A shows two HRP-laden lysosomes in a perinuclear location in a neuronal cell body, while Fig. 2B, C illustrate HRP reaction product in lysosomes located in the proximity of the Golgi apparatus, in a zone of rather high mitochondrial content. Both micrographs also indicate the absence of an HRP-positive reaction in or alongside the exterior of the cisternae of the endoplasmic reticulum. Figure 2D illustrates the occasional appearance of HRP reaction product in the neuropil which, however, was always confined to the outside of the nerve terminals. The occurrence of HRP in the cytoplasm of glial cells is shown in Fig. 2E, F. Figure 2E illustrates HRP reaction product in lysosomes of a medium-shade oligodendrocyte (21), while Fig. $2 \mathrm{~F}$ documents the presence of HRP reaction

15. Staining is sparse and only some cells are involved. B. Conditions as in A. Details of a neuron are shown in which the cytop.asm stains but the processes are devoid of reaction product. C. Fifteen milligrams of HRP (Type II) were administered. Staining is more intense, although even at this concentration of the tracer, it is irregular; some penetration of the reaction product into the processes may be seen. D. Conditions as in $\mathrm{C}$; this is another example of the irregular staining pattern which involves some cells strongly, but other cells quite weakly. $\mathrm{E}$. Conditions as in $\mathrm{C}$; the granular deposition of the reaction product involves the cytoplasm and the processes but not the nucleus. F. Another example of a strongly reactive neuron; the totally black round or cylindrical objects in the photographs denote reaction product in blood vessels. A-D, $\times 1000 ; \mathrm{E}, \mathrm{F}, \times 1600$. 


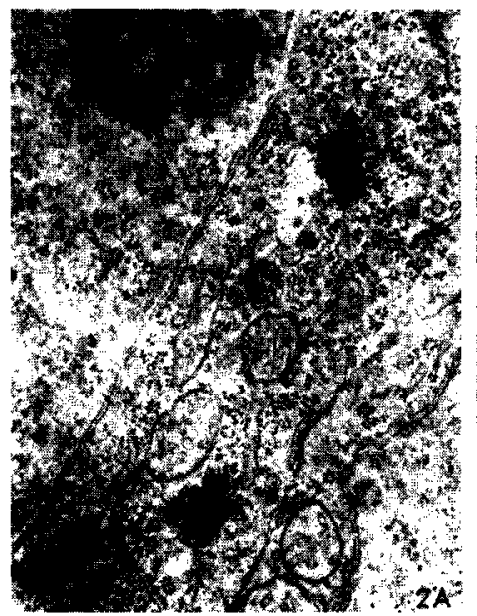

(a)

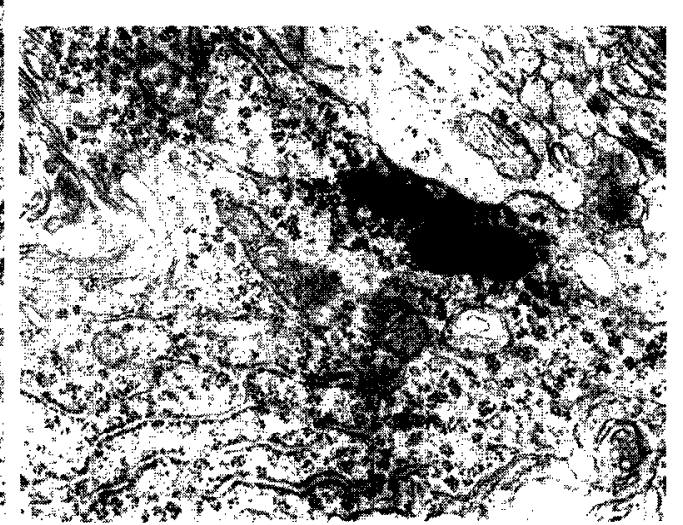

(b)

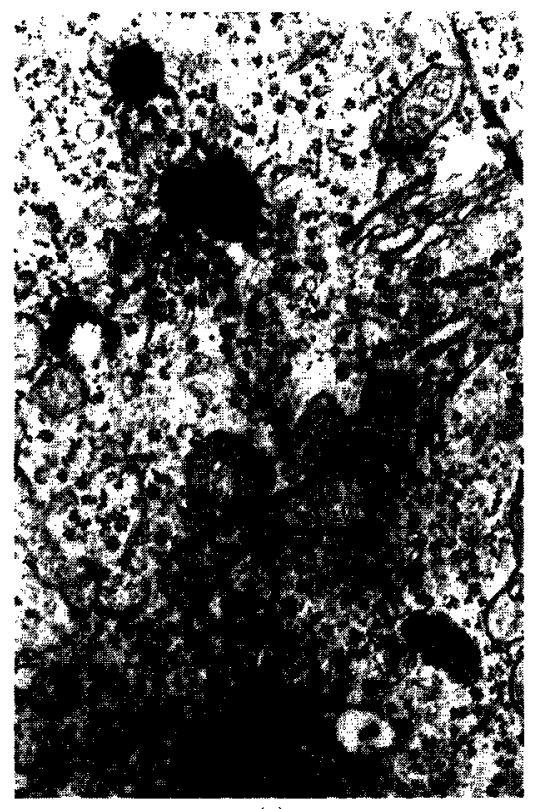

(c)

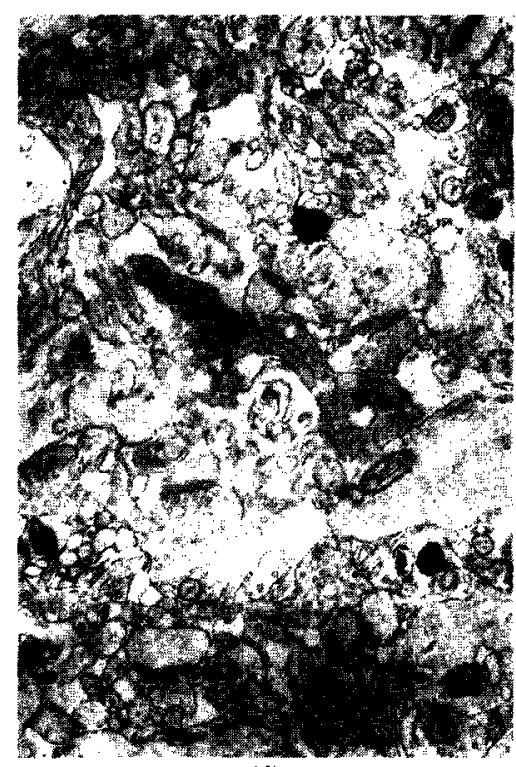

(d)

FIG. 2, A-D. A. Portion of a neuronal cell body showing deposition of HRP reaction product in lysosomes. All other intracellular structures arc negative. B. HRPreaction product may be seen in two discrete organelles. No reaction elsewhere in the cell, including the Golgi cisternae and the membranes of the rough endoplasmic reticulum. C. Another example of intense staining within membrane-bounded organelles. Mitochondria are always negative. $\mathrm{A}-\mathrm{C}$ are from an experiment in which a total of $10 \mathrm{mg}$ of HRP (type II) was injected intracerebrally. D. Ten milligrams of HRP (type VI) were injected over a period of 3 days. A portion of the neuropil is shown. HRP-reaction product is seen within discrete bodies which are never located in nerve endings. A-C, $\times 16,500 ; \mathrm{D}, \times 13,500$. 


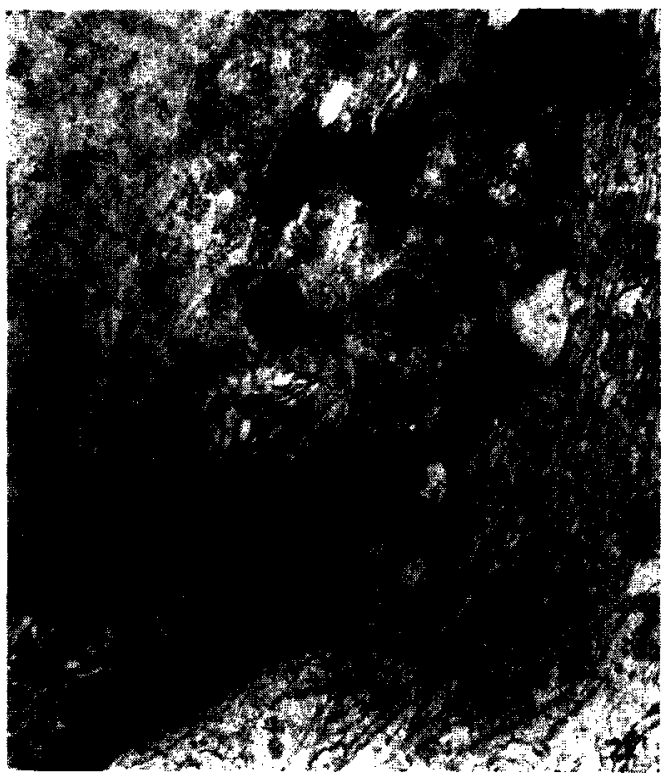

(e)

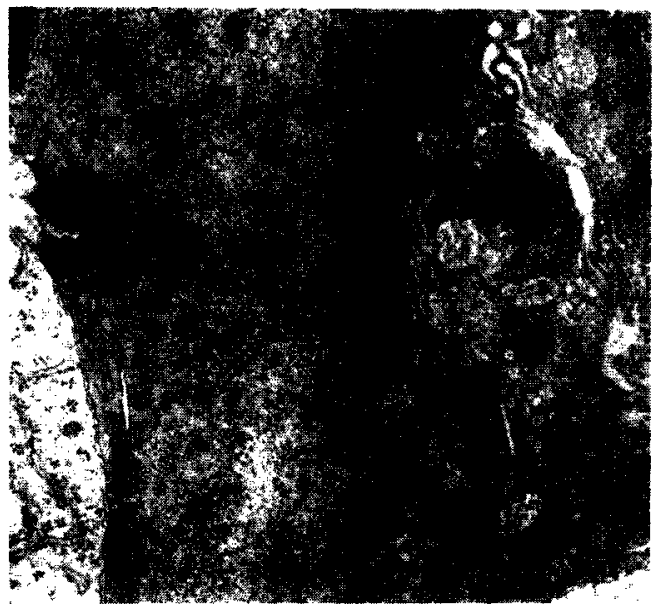

(f)

Fig. 2, E, F. E. Conditions of injection, as in A-C. A medium-shade (21) oligodendrocyte is shown with a rather heavy accumulation of HRP-reaction product in its cytoplasm. F. The cytoplasm of a dark-shade oligodendrocyte (21) shows intense accumulation of HRP-reaction product. $\mathrm{E}, \times 13,500 ; \mathrm{F}, \times 16,500$.

product in the perinuclear region of the cytoplasm of what appears to be a dark-shade oligodendrocyte (21).

Additional morphological evidence for the in vivo segregation of the injected HRP into the lysosomes of neurons was obtained by demonstrating 

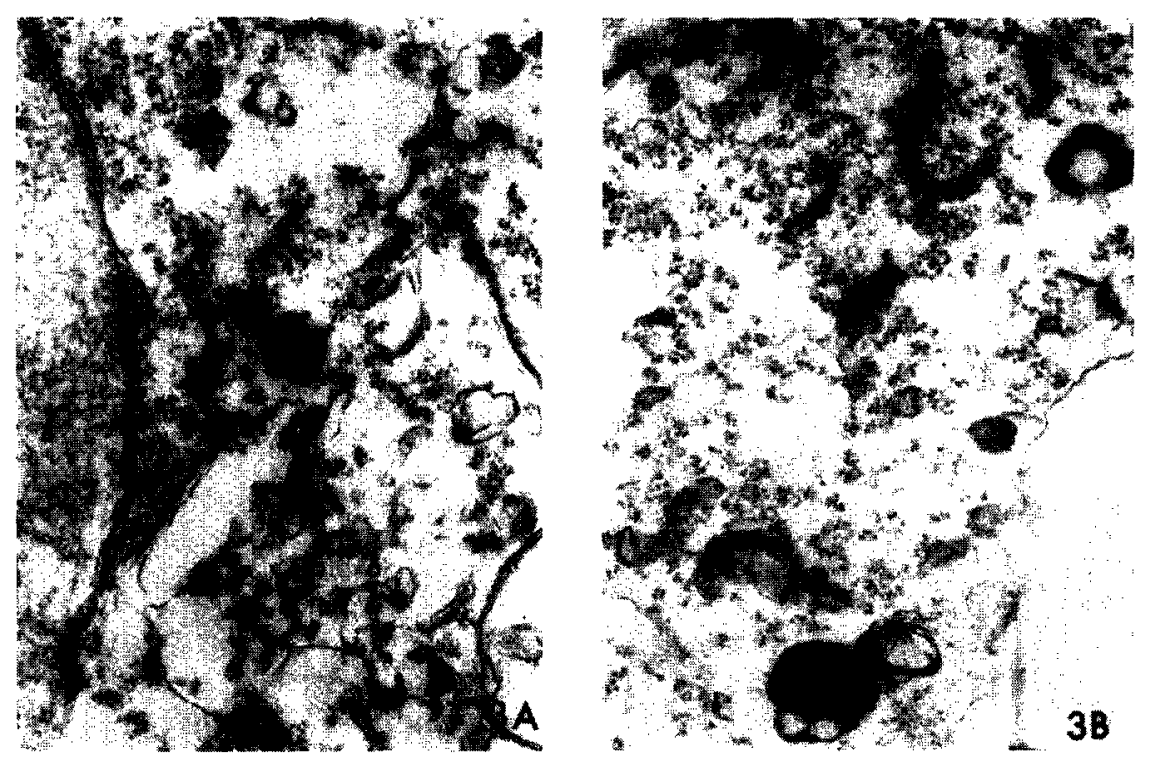

FIG. 3. A. The cytoplasm of a neuronal cell body isolated by the bulk procedure of Sellinger $e t$ al. (33) from the cerebral cortex of a rat which received a total of 10 $\mathrm{mg}$ of type VI HRP, as described in Methods. Accumulation of HRP-reaction product in a lysosome-like organelle is shown. B. Another example of the HRPreaction product in the cytoplasm of a bulk-isolated neuronal cell body. The deposition is within annular profiles and in a structure resembling a multivesicular body (13). $\times 24,600$.

the presence of HRP reaction product in bulk-isolated neuronal cell bodies (33). Figure 3A, B shows portions of the cytoplasm of two isolated neuronal cell bodies in which accumulation of HRP reaction product is clearly seen inside a round, membrane-enclosed body (Fig. 3A) or, alternatively, within cuplike and vacuolated structures previously referred to as being integral components of the neuronal lysosomal system (13).

Biochemical Evidence for the Presence of the Injected HRP in Neuronal Lysosomes. Neuronal cell bodies were isolated from brain cortices of control and HRP-injected rats and the presence of HRP was verified in vitro in whole cell homogenates and in a subcellular fraction obtained by differential centrifugation. Table 1 shows the results of tests for peroxidase activity in two experiments in which HRP was injected either intracerebrally (Expt. 1) or intraperitoneally (Expt. 2). The "fine" localization of the injected HRP in a lysosome-rich subfraction (Fig. 4) (16) of the primary lysosomal fraction (30) is plotted in Fig. 5. Also shown in this graph are the specific activity distribution profiles of the lysosomal marker enzyme $N$-acetyl- $\beta$-D-glucosaminidase in neurons of control (dotted line) and intracerebrally injected (dashed line) animals; the administration of 
TABLE 1

Peroxidase Activity in Vitro in Bulk-Isolated Neukons

\begin{tabular}{cc}
\hline & $\begin{array}{c}\text { Peroxidase activity } \\
\left(\Delta A_{615} / 60 \mathrm{sec}\right)\end{array}$ \\
\hline Expt $1^{a}$ & 0.034 \\
Controls & 0.174 \\
HRP-injected & \\
Expt $2^{b}$ & 0.257 \\
Controls & 0.409 \\
HRP-injected & \\
\hline
\end{tabular}

${ }^{a}$ Rats received a total of $6 \mathrm{mg}$ of HRP (type VI) intracerebrally. They were 6 days old when killed. A mitochondrial fraction (about $0.45 \mathrm{mg}$ of protein/assay) isolated as described in Ref. 31 was used as the source of HRP activity.

${ }^{b}$ Rats received a total of $10 \mathrm{mg}$ of HRP (type VI) intraperitoneally. They were 8 days old when killed. A neuronal homogenate (33) (about $1.7 \mathrm{mg}$ of protein/assay) was used as the source of HRP activity. In both experiments the values shown have been corrected for tissue-free blanks, containing substrate and $\mathrm{H}_{2} \mathrm{O}_{2}$.

HRP resulted, inter alia, in a marked decrease of the specific activity of the lysosomal hydrolase, a finding which was confirmed in a separate experiment in which HRP was administered intraperitoneally, once a day for 3 days and the glucosaminidase was assayed on the fourth day.

\section{DISCUSSION}

The possibility that the adult brain is capable of taking up macromolecular tracers such as HRP via a mechanism involving a relatively unobstructed passage through the blood-brain barrier system has been investigated over the years by several laboratories, including our own (34). Straus (37) injected rather impure HRP intravenously into $400 \mathrm{~g}$ rats and found no evidence for its presence in the brain $15 \mathrm{hr}$ later. Brightman (4) observed that HRP crossed the endothelium of the choroid plexus after its intravenous administration to mice (5), and also noted its penetration into the epithelial basement membrane. A study of the movement of HRP after its intraventricular administration to mice revealed some uptake by the epithelial cells of the choroid plexus and its ready passage "between neighboring ependymal cells to enter the interstices of the underlying cerebral neuropil." The HRP was also observed to enter dendrites and presynaptic terminals, the latter presumably by a mechanism involving pinocytosis. In a subsequent study, Becker, Hirano and Zimmerman (1) reported preliminary observations of the extracellular and intra- 


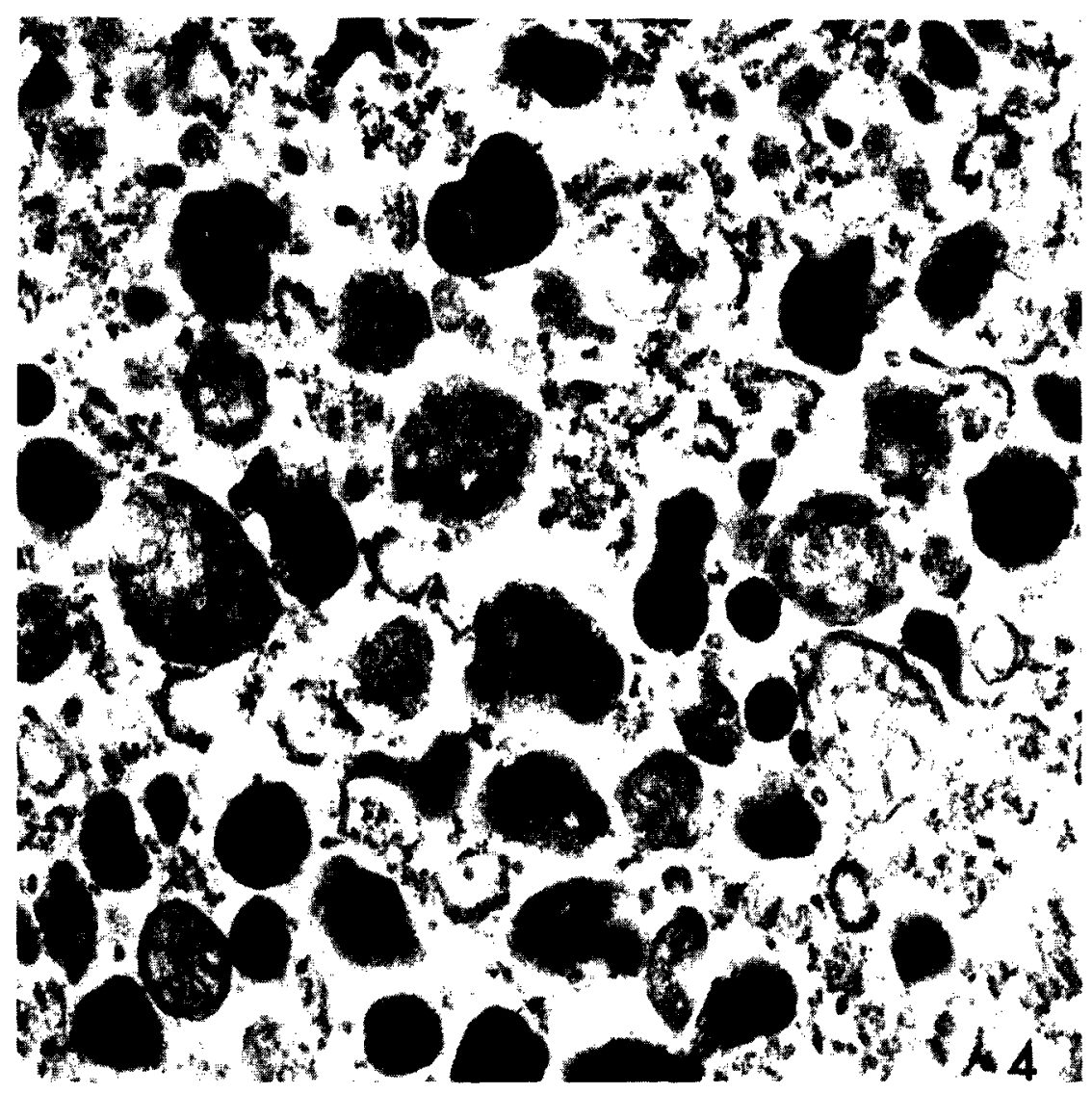

FIG. 4. Neuronal cell bodies were isolated from 8 -day-old rats $(16,33)$ and the primary lysosomal fraction subjected to density-gradient centrifugation as described in Methods. The micrograph is of the contents of gradient tuhe No. 4. Numerous lysusomes may be seetr. $\times 40,800$.

cellular distribution of $0.5-1 \mathrm{mg}$ of Sigma II type HRP implanted in the cerebrum of the adult rat. Examination of the brains 18-24 hr after implantation showed reaction product in gray and white matter. Localization of the tracer in neuronal cell bodies and dendrites was also noted. Reaction product concentrated in vesicles and was also observed in segments of the smooth endoplasmic reticulum within dendrites. More recently, most of these observations have been confirmed in a study of the uptake of HRP by neurons of animals subjected to a number of conditions resulting in the abnormal permeability of the blood-brain barrier (24) and in a related study of the uptake of HRP at the lobster neuromuscular junction (15).

The present study provides a direct demonstration of the uptake of HRP by neurons and neuroglial cells of the immature brain cortex. In a related 
developmental study, Morecki, Zimmerman and Becker (20) injected HRP by different routes, intravenously or intraplacentally to pregnant mothers, into the tail veins of rat fetuses delivered by cesarean section or intraperitoneally into neonates and tested the deposition of HRP reaction product in the choroid plexus 10-60 min later. These workers concluded that transport of HRP from the vascular compartment to the choroid epithelial cells does not occur until about 5 days postnatally. Our results, however, indicate that HRP is readily taken up by cortical neurons of rats 4-6 days old, provided its administration (intracerebral or intraperitoneal) is repeated at least twice (Table 1 ). The intensity of the HRP reaction as illustrated by light microscopy, was a function of the total dose administered. Thus, when $5 \mathrm{mg}$ were given (Fig. 1A, B) granule deposition was spotty and moderate with only a few cells showing areas of diffuse cytoplasmic reactivity. The administration of $15 \mathrm{mg}$ of HRP, on the other hand, resulted in more intense staining of a somewhat grcatcr number of cells (Fig. 1C, D) as well as in a rather conspicuous deposition of HRP reaction product in granules located within the dendritic processes (Fig. $1 \mathrm{E}, \mathrm{F}$ ). Our results with MP (Fig. $1 G, \mathrm{H}$ ) revealed that this small molecular tracer (MW:1900) (6) was readily taken up in large amounts by some cells and virtually not at all by others. A process of uptake selectivity, whose mechanism remains totally obscure at this time, thus enabled the passage of HRP through the membrane of some neurons but not through that of many others. It would be of interest to know whether a yet smaller molecular tracer, such as the recently introduced ferrous gluconate (MW:500) (3), exhibits a similar selective behavior.

On the ultrastructural level, our observations (Fig. 2A-F) extend those of Becker, Hirano and Zimmerman (1), inasmuch as they show the detailed morphology and the intracytoplasmatic localization of the HRPpositive granules in both neuronal cell bodies (Fig. 2A-D) and in neuroglial cells (Fig. 2E, F). We always observed the same pattern of deposition of the HRP reaction product, namely contained inside organelles bounded by a single membrane. The intensity of product deposition was moderate to very strong virtually filling the organelles to the brim. Topographically, the HRP-laden organelles, which we take to be lysosomes, were situated where lysosomes are usually found, that is in the vicinity of the Golgi and the endoplasmic reticulum apparati .The HRP reaction product deposition was never observed along the length of the outer surface of the endoplasmic reticulum membranes, whether smooth or ribosomestudded. Possibly, had we made our observations sooner than on the fourth day after the administration of HRP began, transit of the tracer through the endoplasmic reticulum and the Golgi cisterns may have been detected. The neuroglial cells containing HRP-reaction product were identified as 


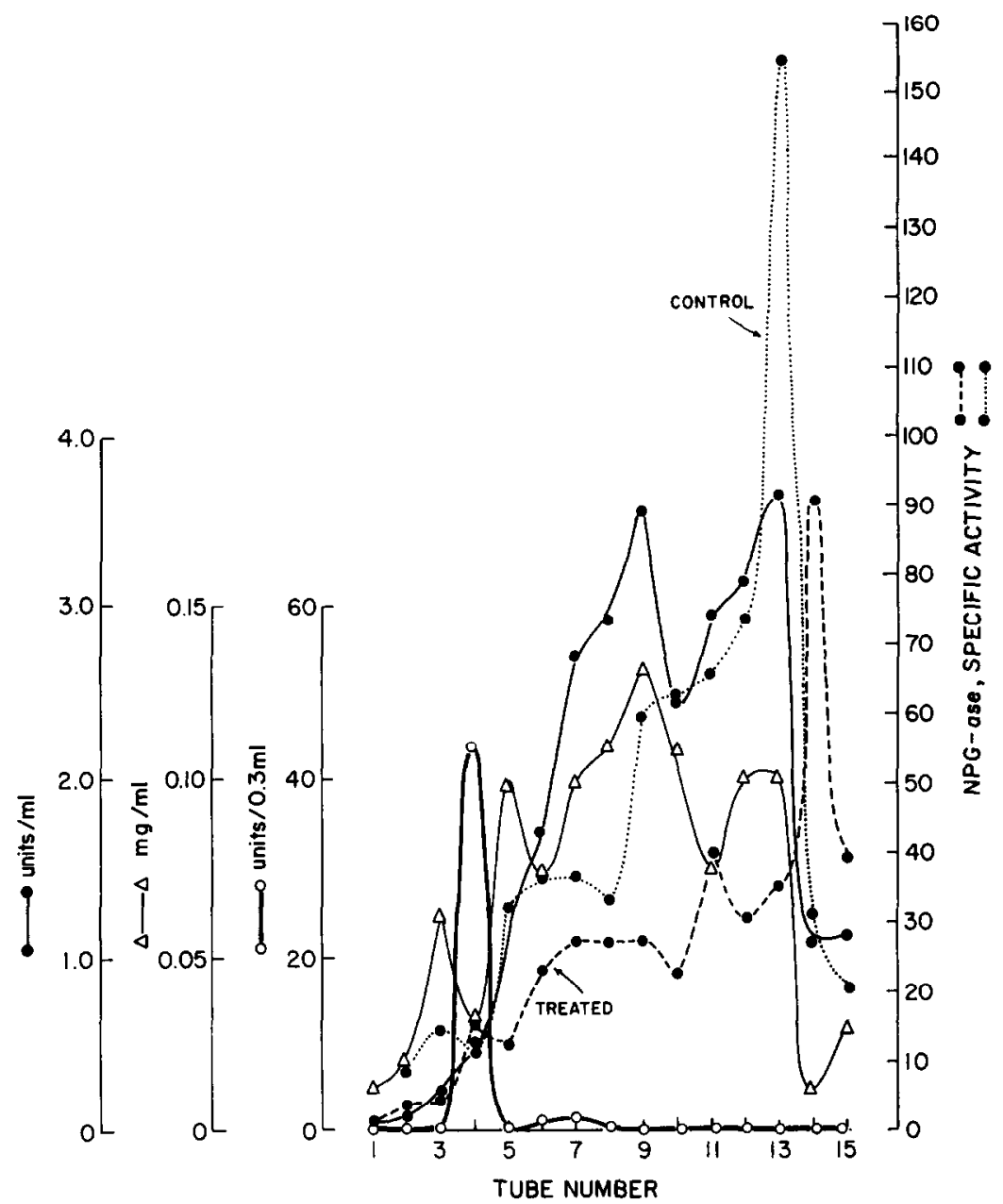

FIG. 5. Density gradient distribution profile of HRP and of the lysosomal $N$ acetyl- $\beta$-D-glucosaminidase. Six 4 -day-old male rats were injected intracerebrally with HRP (type VI) for 2 days. A total dose of $6 \mathrm{mg}$ was administered to each animal. The animals were killed on the sixth postnatal day and the neuronal cell bodies isolated from the pooled cerebral cortices (33). A primary lysosomal fraction was prepared (30) and the lysosomal pellet suspended in $2 \mathrm{ml}$ of $0.25 \mathrm{M}$ sucrose by gentle manual homogenization. The suspension was layered on a $35-60 \%$ $(w / v)$ linear gradient of sucrose and the tubes were centrifuged in rotor SW-41. A control batch of cortices obtained from rats injected with saline was carried through the procedure in parallel. The gradient was divided into 15 portions each of which was assayed for HRP, $N$-acetyl- $\beta$-D-glucosaminidase activity and protein. The left ordinate refers to HRP $(\mathrm{O}-\mathrm{O})$, protein $(\triangle-\triangle)$ and the $N$-acetyl- $\beta$ - $D-$ glucosaminidase (- $)$ of the HRP-injected lysosomal fraction. The right ordinate refers to the specific activity of control and HRP-treated $N$-acetyl- $\beta$-Dglucosaminidase obtained by dividing the enzyme units (optical density at $412 \mathrm{~nm}$ ) per milliliter by the protein content in milligrams per milliliter. Note the sharp peak 
oligodendrocytes simply on the basis of their shading (21) and their definitive typing must await more extensive observations. However, in spite of the fact that only a limited number of glial profiles was actually examined, our impression is that the concentration of the HRP reaction product per cell was higher in the neuroglia than in the neurons. This conclusion agrees with the observations of Brightman (4) and with those of Lane and Treherne (18) on the nervous system of the cockroach. Yet, our results in no way document or, for that matter, preclude, a mechanism of "sequential" uptake of HRP, involving first the glial and only secondly, the neuronal system (or compartment).

Deposition of HRP-reaction product, as illustrated in Fig. 2D, also occurred in the neuropil; yet we never observed an HRP-positive reaction within nerve terminals, clearly characterized by their content of synaptic vesicles. Very infrequently we noted that some synaptic junctions appeared to stain "darker tlan normal," an observation previously made by Becker, Hirano and Zimmerman (1).

Granules containing HRP reaction product were also noted in the cytoplasm of bulk-isolated neuronal perikarya (Fig. 3A, B) (33). The appearance of these HRP-laden organelles was sometimes reminiscent of the cuplike structures and of the multivesicular bodies seen in the perikarya of the adrenal gland and shown by Holtzman (13) to take up exogenous HRP.

Table 1 documents the presence of biochenically assayable HRP in bulk-isolated neuronal cell bodies, while Fig. 5 depicts its association with a lysosome-rich fraction isolated by density gradient centrifugation. Of particular significance was the specific association of HRP activity with a single population of rather dense granules sedimenting in tube No. 4 (Fig. 5); we have shown in separate experiments (16), that this gradient zone is very rich in lysosomes (Fig. 4). Furthermore, this finding, documented in more detail elsewhere (16), supports the concept of a qualitative microheterogencity of the lysosomes in the 6-day-old cortical neuron. The sedimentation profiles of Fig. 5 also indicate that the administration of HRP to 4-day-old rats resulted, inter alia, in a marked reduction of the specific activity of lysosomal $N$-acetyl- $\beta$-D-glucosaminidase in all neuronal lysosomes. Whether the repeated administration of HRP to infant rats results in permanent damage to the neuronal lysosomal apparatus and in a related stunting of their growth is presently under investigation.

of HRP activity in tube No. 4 which contains abundant numbers of lysosomes as indicated by Fig. 4 and the markedly lower than control specific activity profile of the $N$-acetyl- $\beta$-D-glucosaminidase in the lysosomal fraction of the HRP-injected animals. 


\section{REFERENCES}

1. Becker, N. H., A. Hirano, and H. M. Zimmerman. 1968. Observations of the distribution of exogenous peroxidase in the rat cerebrum. J. Neuropathol. Exp. Neurol. $27: 439-452$.

2. Blomstrand, C., and A. Hamberger, 1969. Protein turnover in cell enriched fractions from rabbit brain. J. Neurochem. 16: 1401-1407.

3. Brayser, M., J. R. Casiey-Smith, and B. Green. 1971. $\Lambda$ ncw small molccular tracer for permeability studies with the electron microscope. Experientia 27 : 115-116.

4. Brightman, M. W. 1968. The intracerebral movement of proteins injected into blood and cerebrospinal fluid of mice. Progr. Brain Res. $29: 19-40$.

5. Brightman, M. W., I. Klatzo, Y. Olsson, and T. S. Reese. 1970. The bloodbrain barrier to proteins under normal and pathological conditions. J. Neurol. Sci. $10: 215-239$.

6. FEDER, N. 1971. Microperoxidase. An ultrastructural tracer of low molecular weight. J. Cell Biol. 51 : 339-343.

7. FEDER, N. 1970. A heme-peptide as an ultrastructural tracer. J. Histochem. Cytochem. 18 : 911-913.

8. Flangas, A. L., and R. E. Bowman. 1968. Neuronal perikarya of rat brain isolated by zonal contrifugation. Science 161: 1025-1027.

9. Freysz, L., R. Bieth, C. Judes, M. Sensenbrenner, M. Jacob, and P. Mandel. 1968. Quantitative distribution of phospholipids in neurons and glial cells isolated from rat cerebral cortex. J. Neurochem. $15: 307-313$.

10. Grongi, P. P. 1971. Preparation of neurons and glial cells from rat brain by zonal centrif ugation. Exp. Cell Res. $68: 273-282$.

11. Graham, R. C., and M. J. Karnovsky. 1966. The early stages of absorption of injected horseradish peroxidase in the proximal tubules of mouse kidney: ultrastructural cytochemistry by a ncw tcchnique. J. Histochem. Cytochem. 14 : 291-302.

12. Hemminki, K., M. O. Huttunen, and J. Jarnefelt. 1970. Some properties of brain cell suspensions prepared by a mechanical-enzymic method. Brain Res. $23: 23-34$.

13. Holtzman, E. 1971. Cytochemical studies of protein transport in the nervous system. Phil. Trans. Roy. Soc. Lond. Ser. B. $261:$ 407-421.

14. Holtzman, E., and E. R. Peterson. 1969. Uptake of protein by mammalian neurons. J. Cell Biol. $40: 863-868$.

15. Holtzman, E., A. R. Freeman, and L. A. Kashner. 1971. Stimulation-dependent alterations in peroxidase uptake at lobster neuromuscular junction. Science 173 : 733-736.

16. Inoyaga-Vargas, V., J. C. Santiago, P. D. Petiet, and O. Z. Sellinger. 1972. The early post-natal development of the neuronal lysosome. J. Neurochem. 19: 2533-2544.

17. Johnson, D. E., and O. Z. Sellinger. 1971. Protein synthesis in neurons and glial cells of the developing rat brain: an in viv'o study. J. Neurochem. 18: 1445-1460.

18. LAne, N. J., and J. E. Tremerne. 1970. Uptake of peroxidase by the cockroach central nervous system. Tissue Cell 2 : 413-425.

19. Medzihradsky, F., P. S. Nandhasri, V. Idoyaga-Vargas, and O. Z. Sellinger. 1971. A comparison of the ATPase activity of the glial cell fraction and the neuronal perikaryal fraction isolated in bulk from rat cerebral cortex. $J$. Neurochem. 18 : 1599-1603. 
20. Morecki, R., H. M. Zimmerman, and N. H. BeCker. 1969. Transport of peroxidase by the developing rat choroid plexus. Acta Neuropathol. 14: 14-18.

21. Mori, S., and C. P. Leblond. 1970. Electron microscopic identification of three classes of oligodendrocytes and a preliminary study of their proliferative activity in the corpus callosum of young rats. J. Comp. Neurol. 139: 1-30.

22. Norton, W. T., and S. E. Ponuslo. 1970. Neuronal soma and whole neuroglia of rat brain: a new isolation technique. Science $167: 1144-1145$.

23. Norton, W. T., and S. E. Poduslo. 1971. Neuronal perikarya and astroglia of rat brain: chemical composition during myelination. J. Lipid Res. 12: 84-90.

24. Olsson, Y., and K. A. Hossman. 1970. Fine structural localization of exudated protein tracers in the brain. Acta Neuropathol. 16:103-116.

25. Popuslo, S. E., and W. T. Norton. 1972. Isolation and some chemical properties of oligodendroglia from calf brain. J. Neurochem. 19: 727-736.

26. Radin, N. S., A. Brenkert, R. C. Arora, O. Z. Sellinger, and A. L. Flangas. 1972. Glial and neuronal localization of cerebroside-metabolizing enzymes. Brain Res. 39 : 163-169.

27. Raghavan, S., and J. N. Kanfer. 1972. Ceramide galactoside of enriched neuronal and glial fractions from rat brain. J. Biol. Chem. 247: 1055-1056.

28. Rose, S. P. R. 1967. Preparation of enriched fractions from cerebral cortex containing isolated, metabolically active neuronal and glial cells. Biochem. J. 102: $33-43$.

29. Satake, M., and S. ABe. 1966. Preparation and characterization of nerve cell perikaryon from rat cerebral cortex. J. Biochem. (Tokyo) 59: 72-75.

30. Sellinger, O. Z., and F. de Balbian Verster. 1962. Glutamine synthetase of rat cerebral cortex: intracellullar distribution and structural latency. J. Biol. Chem. $237: 2836-2844$.

31. Seliminger, O. Z., D. L. Rucker, and F. de Balbian Verster. 1964. Cerebral lysosomes-I. A comparative study of lysosomal $N$-acetyl- $\beta$-D-glucosaminidase and mitochondrial aspartic transaminase of rat cerebral cortex. J. Ncurochem. 11: 271-280.

32. Sellinger, O. Z., W. G. Ohlsson, A. J. Frankel, J. M. Azcurra, and P. D. Petiet. 1971. A study of the nascent polypeptides synthesized on the free polyribosomes of rat brain in vivo. J. Neurochcm. 18: 1243-1260.

33. Sellinger, O. Z., J. M. Azcurra, D. E. Johnson, W. G. Ohlsson, and Z. LoDIN. 1971. Independence of protein synthesis and drug uptake in nerve cell bodies and glial cells isolated by a new technique. Nature (London) Ncre Biol. 230 : 253-256.

34. Sellinger, O. Z., L. Nordrum, and V. Idoyaga-Varagas. 1971. Cerebral Lysosomes. VI. The in vivo uptake of triton-WR-1339 by the lysosomes of the immature cerebral cortex and cerebellum. Brain Res. 26 : 361-373.

35. Sellinger, O. Z.. and J. C. Santiago. 1972. Unequal development of two mitochondrial enzymes in neuronal cell bodies and glial cells of rat cerebral cortex. Neurobiology 2 : 133-146.

36. Sinha, A. K., and S. P. R. Rose. 1971. Bulk separation of neurones and glia: A comparison of techniques. Brain Res. 33 : 205-217.

37. Stratus, W. 1958. Colorimetric analysis with $N, N$-dimethyl-p-phenylenediamine of the uptake of intravenously injected horseradish peroxidase by various tissues of the rat. J. Biophys. Biochem. Cytol. $4: 541-550$.

38. Tamai, Y., S. Matslikawa, and M. Satake. 1971. Lipid composition of nerve cell perikarya. Brain Res. $26: 149-157$. 